\title{
openheart Intermittent systemic hypoxic- hyperoxic training for myocardial protection in patients undergoing coronary artery bypass surgery: first results from a single-centre, randomised controlled trial
}

\author{
Denis S Tuter, ${ }^{1}$ Philippe Y Kopylov, ${ }^{1}$ Abram L Syrkin, ${ }^{1}$ Oleg S Glazachev, ${ }^{1}$ \\ Roman N Komarov, ${ }^{1}$ Andrei I Katkov, ${ }^{1}$ Ljudmila P Severova, ${ }^{1}$ Ekaterina V Ivanova, ${ }^{1}$ \\ Young Zhang, ${ }^{2}$ Hugo Saner ${ }^{1,3}$
}

To cite: Tuter DS, Kopylov PY, Syrkin AL, et al. Intermittent systemic hypoxic-hyperoxic training for myocardial protection in patients undergoing coronary artery bypass surgery: first results from a single-centre, randomised controlled trial. Open Heart 2018;5:e000891. doi:10.1136/ openhrt-2018-000891

Received 1 July 2018 Revised 19 August 2018 Accepted 20 September 2018

(D) Check for updates

(C) Author(s) (or their employer(s)) 2018. Re-use permitted under CC BY-NC. No commercial re-use. See rights and permissions. Published by BMJ.

${ }^{1}$ IE Sechenov First Moscow State Medical University, Moscow, Russia

${ }^{2}$ Harbin Medical University, Harbin, China

${ }^{3}$ University Clinic for Cardiology, University Hospital, Inselspital, Bern, Switzerland

\section{Correspondence to}

Hugo Saner; hugo.saner@ insel.ch

\section{ABSTRACT}

Background Although remote ischaemic preconditioning (RIP) provides protection against myocardial ischaemia and reperfusion injury during cardiac surgery, it is not widely used. Systemic intermittent hypoxic-hyperoxic training (IHHT) may be a suitable alternative.

Methods This is a prospective, single-centre, randomised controlled trial. 127 patients with ischaemic heart disease and indication for coronary artery bypass graft (CABG) surgery from the Cardiology Clinic IM Sechenov First Moscow State Medical University were randomly assigned to IHHT, IHHT-control or RIP. Primary endpoint was serum concentration of troponin I and lactate 2 and 24 hours after surgery.

Results Median value for troponin I 24 hours after surgery was $1.068(0.388-1.397) \mathrm{ng} / \mathrm{mL}$ in the IHHT group and was significantly lower compared with IHHT-controls with $1.980(1.068-3.239) \mathrm{ng} / \mathrm{mL}(\mathrm{p}=0.012)$ and to the RIP group with $1.762(1.288-2.186) \mathrm{ng} / \mathrm{mL}(\mathrm{p}=0.029)$, while there was no significant difference between RIP and the IHHT-control. Serum lactate after surgery was 1.74 (1.232.04) $\mathrm{mmol} / \mathrm{L}$ in the IHHT group and was also significantly lower compared with IHHT-controls with 2.10 (1.80-2.29) $\mathrm{mmol} / \mathrm{L}(\mathrm{p}=0.045)$ and RIP with $2.12(1.91-2.33) \mathrm{mmol} / \mathrm{L}$ $(p=0.032)$. No significant complications or serious adverse events were observed during IHHT. Intraoperative and early postoperative complications did not differ significantly between groups.

Conclusions The results of this first trial using IHHT for myocardial protection against perioperative ischaemic myocardial injury in patients undergoing CABG surgery are promising and further larger trials should be done with adequate power to detect clinical rather than surrogate marker benefits.

\section{INTRODUCTION}

In cardiac and coronary artery bypass graft (CABG) surgery, adverse outcome is related

\section{Key messages}

What is already known about this subject?

- There is no scientific evidence for the effects of systemic intermittent hypoxic-hyperoxic training as an alternative to remote ischaemic preconditioning for myocardial protection from injury by myocardia ischaemia and reperfusion during cardiac surgery.

What does this study add?

- The results of this first study evaluating safety and effectiveness of systemic intermittent hypoxic-hyperoxic training for myocardial protection from perioperative ischaemia and reperfusion injury during elective aortocoronary bypass surgery are promising. Further larger trials should be done with adequate power to evaluate safety and clinical benefits of this intervention

How might this impact on clinical practice?

- Systemic intermittent hypoxic-hyperoxic training may turn out to be a suitable alternative to remote ischaemic preconditioning for myocardial protection from ischaemia and reperfusion injury during elective aortocoronary bypass surgery.

to a great extent to perioperative myocardial injury. ${ }^{1}$ Remote ischaemic preconditioning (RIP) by brief episodes of ischaemia and reperfusion in a remote vascular territory or organ has shown to provide perioperative myocardial protection and improved the prognosis of patients undergoing elective CABG surgery. ${ }^{2}{ }^{3}$ Furthermore, randomised controlled trials have shown decreased release of myocardial biomarkers after CABG surgery, ${ }^{4}$ congenital cardiac and valve surgery. ${ }^{5}{ }^{6}$ However, despite its beneficial effects, RIP is not widely used. This is mainly 
because beneficial effects are marginal and even controversial, and because the practicality of the intervention in the early phase of anaesthesia and immediately before surgery seems not to be very appealing. Therefore, RIP may not be a suitable intervention for widespread use under such conditions.

The purpose of this first randomised controlled trial was to evaluate the safety and efficacy of a systemic intermittent hypoxic-hyperoxic training (IHHT) for protection against myocardial injury from ischaemia and reperfusion during elective CABG surgery and to compare results with those of RIP and with those of an IHHT-control group.

\section{METHODS}

\section{Study design and participants}

This is a prospective, single-centre, randomised controlled trial. Patients were recruited consecutively during preadmission consultation at the IE Sechenov First Moscow State Medical University Cardiac Surgery Department. All patients had a diagnosis of coronary artery disease and indications for elective myocardial revascularisation by coronary artery bypass according to the 2014 European Society of Cardiology/European Association for Cardio-Thoracic Surgery guidelines. ${ }^{7}$ Exclusion criteria were additional surgeries planned simultaneously with CABG surgery, occlusive atherosclerotic disease of upper and lower limbs, acute coronary syndrome within 4 weeks before entry, coronary artery bypass without cardiopulmonary bypass, preoperative percutaneous coronary intervention and European heart surgery risk classification (EuroSCORE II) more than 4 including preoperative renal insufficiency (serum creatinine higher than $200 \mathrm{mmol} / \mathrm{L}$ ) and other conditions that could potentially increase perioperative cTnI release. Lack of sufficient time from hospitalisation to surgery for a planned number of training sessions was another exclusion criterion.

The study conforms to the principles of the Declaration of Helsinki.

\section{Randomisation and masking}

Five days before the operation, patients were randomly assigned to three groups using a computer-generated randomisation table: two main groups (IHHT and RIP) and a IHHT-control group. No stratification factors were used and no block randomisation was applied.

\section{Procedures}

Patients in the IHHT group underwent four daily procedures of interval hypoxic-hyperoxic training before CABG surgery using a normobaric device to obtain hypoxic and hyperoxic gas mixtures (ReOxy Cardio; Aimediq S.A., Luxemburg) ${ }^{8}$ Before the start of training, each patient underwent a hypoxic test to assess the individual response to hypoxia and to determine the rate of reduction of blood oxygen saturation $\left(\mathrm{SpO}_{2}\right)$ with a finger pulse oxymeter (Masimo SET, measurement accuracy $\pm 2 \%$ ). During $5 \mathrm{~min}$, the patient received air with reduced oxygen content $(12 \%)$ through a mask under constant monitoring of heart rate (HR) and $\mathrm{SpO}_{2}$. As a safety measure, minimal $\mathrm{SpO}_{2}$ was set at $82 \%$ and maximal accepted increase of HR was set to $+50 \%$ of the initial HR. When these values were reached, the supply of oxygen automatically switched to a hyperoxic gas mixture $\left(35 \%-40 \% \mathrm{O}_{2}\right)$, inhaling of which was continued until $\mathrm{SpO}_{2}$ reached $100 \%$ (even if $\mathrm{SpO}_{2}$ was lower before the procedure), which, depending on the rate of saturation reduction, has taken 1 to 3 min (mean $1 \mathrm{~min}$ and $50 \mathrm{~s}$ ). The intention was to create hyperoxic arterial oxygen tension and not simply to reduce the time required to recover from hypoxia. IHHT was considered successful if there were no significant side effects during the procedure such as angina pain, loss of consciousness, severe dizziness or other variants of significant subjective deterioration of the patient's condition. In case of successfully passing the test, patients proceeded to the basic IHHT training. During the training, the hypoxic gas mixture was given to the patient again in intermittent mode based on the individual test parameters and alternating with the supply of a hyperoxic gas mixture. One cycle of the procedure consisted of 'hypoxic' and 'hyperoxygenated' intervals, the duration of which was regulated automatically according to the biofeedback principle based on monitoring of individual values of $\mathrm{SpO}_{2}$ and HR. Duration of the hypoxic period ranged from 3 to $5 \mathrm{~min}$, and duration of the hyperoxic period was from 1 to $3 \mathrm{~min}$, depending on the $\mathrm{SpO}_{2}$ recovery rate. Total time of the hypoxic gas mixture inhalation during one procedure was $20-30 \mathrm{~min}$. A final training was conducted on the evening before surgery.

Patients in the RIP group underwent RIP before induction of anaesthesia and skin incision. Three cycles of 10 min of ischaemia were applied to the right lower limb at the level of the upper third of the thigh by inflation of a blood pressure cuff to $200 \mathrm{~mm} \mathrm{Hg}$, followed by $10 \mathrm{~min}$ reperfusion while the cuff was deflated. The time from the end of the RIP procedure to the end of cardiopulmonary bypass $(\mathrm{CPB})$ averaged 2 hours and $46 \mathrm{~min}$, and only in three patients the period exceeded 3 hours. Maximum time was 3 hours and $20 \mathrm{~min}$.

Patients in the IHHT-control group also underwent four daily procedures before surgery using $40 \mathrm{~min}$ training periods with simulation of IHHT by using the same equipment, whereas moistened air was delivered through the mask.

Only the person who conducted the training knew about the patient's allocation to a particular intervention group. Anaesthesiologists and cardiac surgeons had no access to this information.

At the time of enrolment, there were no differences between groups in resting HR, systolic and diastolic blood pressure. In the IHHT group, the inhalation period of the hypoxic gas mixture was accompanied by a temporary increase in HR (on average by $15 \%$ ), but HR slowed down to the baseline level with $\mathrm{SpO}_{2}$ normalisation. 
The level of high-sensitivity troponin I was monitored in all patients immediately before, 2 and 24 hours after the operation and was measured using an immunoassay test set (Architect stat, 'Abbott') and an iMark photometer with a detection range of $0.01-40.00 \mathrm{ng} / \mathrm{mL}$; reference range was $0-0.026 \mathrm{ng} / \mathrm{mL}$. Also, the level of lactate in the venous blood was measured before and 24 hours after surgery by a blood gas analyser (RAPIDLab 1200 System; Siemens Healthcare, Erlangen, Germany). Creatinine and glomerular filtration rate were determined at baseline and frequently within the first 2 days of surgery, as per normal hospital procedure.

Episodes of cardiac arrhythmias, hypotension with a need for inotropic drug prescription, changes in ECG, pulse values and blood pressure levels were recorded during surgery and the postoperative period.

CABG surgery was performed by standard operative approach via median sternotomy under condition of $\mathrm{CPB}$ and antegrade cardioplegia (Consol; Custodiol Solutions) through the aortic root with permanent antegrade cerebral perfusion. The same scheme was used as an anaesthesia, including propofol, fentanyl, arduan (pipecuronium bromide) and diazepam. The duration of CPB did not differ between the three groups $(56 \pm 14.8$ min in the IHHT group, $61 \pm 15.9 \mathrm{~min}$ in the RIP group and $59 \pm 15.1 \mathrm{~min}$ in the control group). The aortic clamping time was also not significantly different: $42 \pm 7.3$ $\mathrm{min}$ in the IHHT group, $45 \pm 8.4 \mathrm{~min}$ in the RIP group and $43 \pm 7.8 \mathrm{~min}$ in the control group. The adequacy of CPB was assessed by mean arterial pressure $(60-80 \mathrm{~mm} \mathrm{Hg}$ ), central venous pressure $(8-10 \mathrm{~mm} \mathrm{Hg})$, arterial blood gas and acid-base blood composition analysis.

\section{Statistical analysis}

Statistical analysis of the results was carried out using the SPSS Statistics software V.23.0. Kolmogorov-Smirnov test was performed to assess normal distribution. For variables with normal distribution, the data are represented as the mean and SD and for variables with a non-parametric distribution as median with IQRs (the values of 25th and 75th percentiles are indicated in parentheses). The main characteristics of the groups were compared using Kruskal-Wallis test for independent samples. Due to the non-parametric distributions for troponin and lactate values, the following tests were used: Mann-Whitney $\mathrm{U}$ test for pairwise comparison, the Kruskal-Wallis test for comparison of all three groups and Friedman two-way analysis of variance by ranks for repeated measures in order to determine differences in the dynamics of troponin I and lactate. Differences were considered significant at $\mathrm{p}$ value $<0.05$.

\section{RESULTS}

Of 356 patients screened for the trial, 127 patients were randomised to either systemic IHHT (40), remote RIP (40) or to the IHHT-control group (40), and were included into the final analysis (figure 1). Seven patients

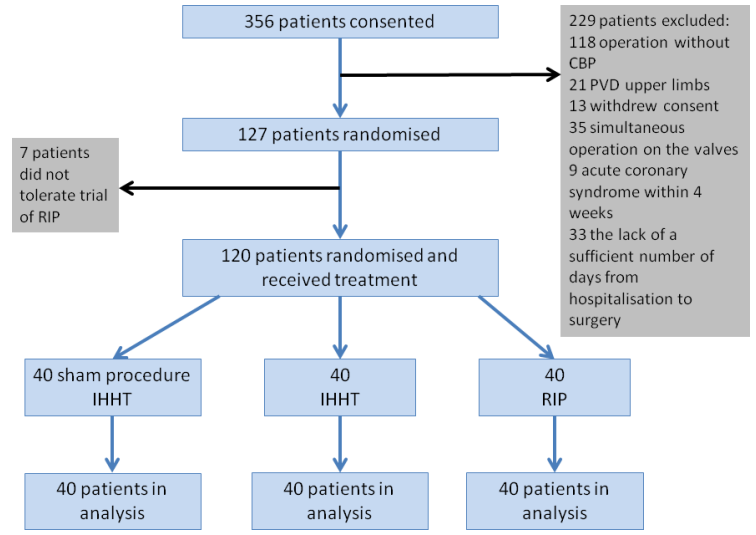

Figure 1 Trial profile. CPB, cardiopulmonary bypass; IHHT, intermittent hypoxic-hyperoxic training; PVD, peripheral vessel disease; RIP, remote ischaemic preconditioning.

had to be excluded before the start of the intervention because they did not tolerate RIP during pre-intervention tests. EuroSCORE II was $1.27 \pm 1.12$ in the IHHT group, $1.24 \pm 1.07$ in the RIP group and $1.17 \pm 0.76$ in the IHHT-control group.

Baseline and intraoperative characteristics (table 1) and preoperative drug therapy (table 2) did not differ between groups.

Significant complications and adverse reactions were not observed during hypoxic tests and IHHT. There were no episodes of angina pectoris, syncopal or presyncopal events. During the first procedures, some patients in the IHHT group had complaints of short-term unexpressed dizziness, which did not require interruption of the procedure. None of the patients refused further participation after the first procedure. Minimal values of $\mathrm{SpO}_{2}$ were $85 \%$ on average; the lowest value of $\mathrm{SpO}_{2}$ was $79 \%$. The duration of the period during which $\mathrm{SpO}_{2}$ decreased to less than $82 \%$ did not exceed 30 s. In the IHHT group, HR increased on average by $15 \%$ during the inhalation of the hypoxic gas mixture.

Incidence of adverse events was significantly higher in the RIP group: seven patients included in this group refused further participation in the study after the first procedure. All participants noted discomfort from mechanical pressure during inflation of the cuff at the thigh, which was the reason for most refusals to participate further. All patients had a feeling of numbness and tingling in the squeezed limb and showed pallor of the skin during the procedure. RIP was accompanied by pain of varying intensity almost in each patient (two patients refused to continue participating because of severe pain, but more often pain were modest and did not require interruption of the procedure).

The frequency of intraoperative and early postoperative complications during inpatient stay is shown in table 3 .

One death was recorded and was due to intraoperative myocardial infarction with subsequent ventricular fibrillation and transition to asystole. There were two episodes of life-threatening arrhythmias (ventricular fibrillation), one of which resulted in the patient's death, whereas the 
Table 1 Baseline characteristics

\begin{tabular}{|c|c|c|c|c|}
\hline Characteristic & $\begin{array}{l}\text { IHHT group }(n=40) \text {, } \\
\text { abs. }(\%)\end{array}$ & $\begin{array}{l}\text { RIP group }(n=40) \text {, } \\
\text { abs. }(\%)\end{array}$ & $\begin{array}{l}\text { Control group } \\
(n=40), \text { abs. }(\%)\end{array}$ & $P$ values \\
\hline Gender, male & $30(75 \%)$ & $33(82.5 \%)$ & $31(77.5 \%)$ & NS \\
\hline Age, years & $63 \pm 8.4$ & $64 \pm 8.1$ & $64 \pm 7.6$ & NS \\
\hline HHB & $38(95 \%)$ & $37(92.5 \%)$ & $37(92.5 \%)$ & NS \\
\hline DM type 2 & $11(27.5 \%)$ & $10(25 \%)$ & $10(25 \%)$ & NS \\
\hline Smoking & $28(70 \%)$ & $31(77.5 \%)$ & $25(62.5 \%)$ & NS \\
\hline \multicolumn{5}{|l|}{ Angina pectoris, FC: } \\
\hline$\|$ & $12(30 \%)$ & $13(32.5 \%)$ & $12(30 \%)$ & NS \\
\hline III & $15(37.5 \%)$ & $19(47.5 \%)$ & $17(42.5 \%)$ & NS \\
\hline IV & $8(20 \%)$ & $5(12.5 \%)$ & $7(17.5 \%)$ & NS \\
\hline Silent myocardial ischaemia & $5(12.5 \%)$ & $3(7.5 \%)$ & $4(10 \%)$ & NS \\
\hline Postinfarction cardiosclerosis & $21(52.5 \%)$ & $20(50 \%)$ & $25(62.5 \%)$ & NS \\
\hline Coronary artery bypass/PCI in the medical history & $7(17.5 \%)$ & $8(20 \%)$ & $6(15 \%)$ & NS \\
\hline Paroxysmal AF & $5(12.5 \%)$ & $5(12.5 \%)$ & $6(15 \%)$ & NS \\
\hline COPD without respiratory failure & $8(20 \%)$ & $11(27.5 \%)$ & $5(12.5 \%)$ & NS \\
\hline No of bypass grafts (median) & $2.58 \pm 0.81$ & $2.5 \pm 0.91$ & $2.52 \pm 0.82$ & NS \\
\hline 1 & $3(7.5 \%)$ & $6(15 \%)$ & $4(10 \%)$ & NS \\
\hline 2 & $16(40 \%)$ & $13(32.5 \%)$ & $15(37.5 \%)$ & NS \\
\hline 3 & $16(40 \%)$ & $16(40 \%)$ & $17(42.5 \%)$ & NS \\
\hline 4 & $5(12.5 \%)$ & $5(12.5 \%)$ & $4(10 \%)$ & NS \\
\hline
\end{tabular}

ABS, absolute number of patients; AF, atrial fibrillation; COPD, chronic obstructive pulmonary disease; DM, diabetes mellitus; FC, functional class; HHB, hypertensive heart disease; IHHT, intermittent hypoxic-hyperoxic training; NS, no significant difference between all three groups; $\mathrm{PCl}$, percutaneous coronary intervention; RIP, remote ischaemic preconditioning.

second one was successfully stopped by defibrillation. All of these events occurred in the control group. However, there were no significant intergroup differences due to the low number of complications.

The incidence of hypotension did not significantly differ between groups. There was a trend towards a decrease in the number of episodes with paroxysmal atrial fibrillation in the IHHT group compared with the other groups. Significant reductions in cognitive function (encephalopathy) requiring consultation by a neurologist were equally rare in both groups.

Table 2 Preoperative drug therapy

\begin{tabular}{|c|c|c|c|c|}
\hline Drug class & $\begin{array}{l}\text { IHHT group }(n=40) \text {, abs. } \\
(\%)\end{array}$ & $\begin{array}{l}\text { RIP group }(n=40) \text {, abs. } \\
(\%)\end{array}$ & $\begin{array}{l}\text { Control group }(n=40) \text {, } \\
\text { abs. }(\%)\end{array}$ & $P$ values \\
\hline \multicolumn{5}{|l|}{ Antithrombotic drugs } \\
\hline Aspirin & $40(100 \%)$ & $37(92.5 \%)$ & 38 (95\%) & NS \\
\hline Clopidogrel & $4(10 \%)$ & $6(15 \%)$ & $6(15 \%)$ & NS \\
\hline Statins & $32(80 \%)$ & $34(85 \%)$ & 29 (72.5\%) & NS \\
\hline Beta-blockers & 25 (62.5\%) & 25 (62.5\%) & 29 (72.5\%) & NS \\
\hline Calcium channel blockers & $18(45 \%)$ & $17(42.5 \%)$ & $20(50 \%)$ & NS \\
\hline ACE inhibitors & $26(65 \%)$ & $30(75 \%)$ & $23(57.5 \%)$ & NS \\
\hline ARB & $8(20 \%)$ & $7(17.5 \%)$ & $4(10 \%)$ & NS \\
\hline Prolonged nitrates & 7 (17.5\%) & $4(10 \%)$ & $8(20 \%)$ & NS \\
\hline Molsidomine & $2(5 \%)$ & $1(2.5 \%)$ & 0 & NS \\
\hline Trimetazidine & $4(10 \%)$ & $6(15 \%)$ & $3(7.5 \%)$ & NS \\
\hline Amiodarone & $3(7.5 \%)$ & $5(12.5 \%)$ & $5(12.5 \%)$ & NS \\
\hline
\end{tabular}

ARB, angiotensin II receptor blocker; IHHT, intermittent hypoxic-hyperoxic training; NS, no significant difference between all three groups; $\mathrm{RIP}$, remote ischaemic preconditioning. 


\begin{tabular}{|c|c|c|c|c|}
\hline Complications & $\begin{array}{l}\text { IHHT group }(n=40) \text {, } \\
\text { abs. }(\%)\end{array}$ & $\begin{array}{l}\text { RIP group (n=40), abs. } \\
(\%)\end{array}$ & $\begin{array}{l}\text { Control group }(n=40), \\
\text { abs. }(\%)\end{array}$ & $P$ values \\
\hline Perioperative myocardial infarction & 0 & 0 & $1(2.5 \%)$ & NS \\
\hline Death & 0 & 0 & $1(2.5 \%)$ & NS \\
\hline Ventricular fibrillation & 0 & 0 & $2(5 \%)$ & NS \\
\hline Hypotension (need for inotropic therapy) & $7(17.5 \%)$ & $8(20 \%)$ & $9(22.5 \%)$ & NS \\
\hline Atrial fibrillation & $8(20 \%)$ & $13(32.5 \%)$ & $12(30 \%)$ & NS \\
\hline Encephalopathy & $2(5 \%)$ & $2(5 \%)$ & $3(7.5 \%)$ & NS \\
\hline Pericarditis & $2(5 \%)$ & $4(10 \%)$ & $1(2.5 \%)$ & NS \\
\hline Hydrothorax (centesis) & $3(7.5 \%)$ & $2(5 \%)$ & $3(7.5 \%)$ & NS \\
\hline \multicolumn{5}{|l|}{ ECG disorders } \\
\hline ST depression & $2(5 \%)$ & $3(7.5 \%)$ & $2(5 \%)$ & NS \\
\hline AV block 2nd degree & $1(2.5 \%)$ & 0 & $2(5 \%)$ & NS \\
\hline Bundle branch block & $1(2.5 \%)$ & $6(15 \%)$ & $5(12.5 \%)$ & NS \\
\hline Overall & 22 & 38 & 39 & NS \\
\hline
\end{tabular}

IHHT, intermittent hypoxic-hyperoxic training; NS, no significant difference between all three groups; RIP, remote ischaemic preconditioning.

There were three episodes of second-degree AV block (Mobitz type I and II) requiring the installation of a temporary pacemaker, but with restoration of atrioventricular node function during follow-up. Seven episodes of short-term ST depression were recorded. Totally, transient ECG changes during the operation were observed less frequently in the IHHT group than in the RIP and the IHHT-control group, but the differences were not significant.

Before and 2 hours after surgery, mean values of serum troponin I and serum lactate were not significantly different between groups (table 4). Twenty-four hours after surgery, statistically significant differences of serum troponin I values (median with IQRs) were found between the groups: median value of troponin I was $1.068(0.388-1.397)$ in IHHT patients and significantly lower compared with $1.762(1.288-2.186) \mathrm{ng} / \mathrm{mL}$ in RIP patients and $1.980(1.068-3.239) \mathrm{ng} / \mathrm{mL}$ in the control group. Mean lactate values 24 hours after surgery were $1.74(1.23-2.04)$ in the IHHT group and again significantly lower compared with $2.12(1.91-2.33) \mathrm{mmol} / \mathrm{L}$ in RIP patients and $2.10(1.80-2.29) \mathrm{mmol} / \mathrm{L}$ in the IHHT-control group (figure 2).
There was no evidence of an influence of IHHT or RIP on the length of stay in the intensive care unit (mean 1 day) and the duration of the overall inpatient stay (mean 6 days).

\section{DISCUSSION}

This study shows for the first time in a randomised controlled trial that IHHT may be effective to protect myocardium against perioperative myocardial injury during elective aortocoronary bypass surgery. Furthermore, IHHT was better tolerated than RIP if performed before anaesthesia. Troponin I levels as biomarker for myocardial injury were statistically significantly lower with IHHT compared with RIP and IHHT-controls. No significant complications were observed during IHHT.

\section{Effects of hypoxia}

Studies of adaptation mechanisms of the human body to the effects of hypoxia started in the first half of the 20th century and have been mainly performed by scientists of the former USSR (Sirotinin NN 1931, Barbashova ZI 1942, Vasilyeva PV 1967, Meerson FZ 1973). They found

Table 4 P values for differences of troponin I and serum lactate between groups

\begin{tabular}{llllll}
\hline & & Troponin I before & Troponin I & Troponin I & \\
Comparable groups & surgery & 2 hours after surgery & $\begin{array}{l}\text { 24 hours after } \\
\text { surgery }\end{array}$ & $\begin{array}{l}\text { Lactate after } \\
\text { surgery }\end{array}$ \\
\hline All three groups & & 0.504 & 0.739 & 0.023 & 0.047 \\
IHHT & RIP & 0.304 & 0.518 & 0.029 & 0.032 \\
IHHT & Control group & 0.341 & 0.891 & 0.012 & 0.045 \\
RIP & Control group & 0.943 & 0.494 & 0.675 & 0.856 \\
\hline
\end{tabular}

$\mathrm{IHHT}$, intermittent hypoxic-hyperoxic training; RIP, remote ischaemic preconditioning. 


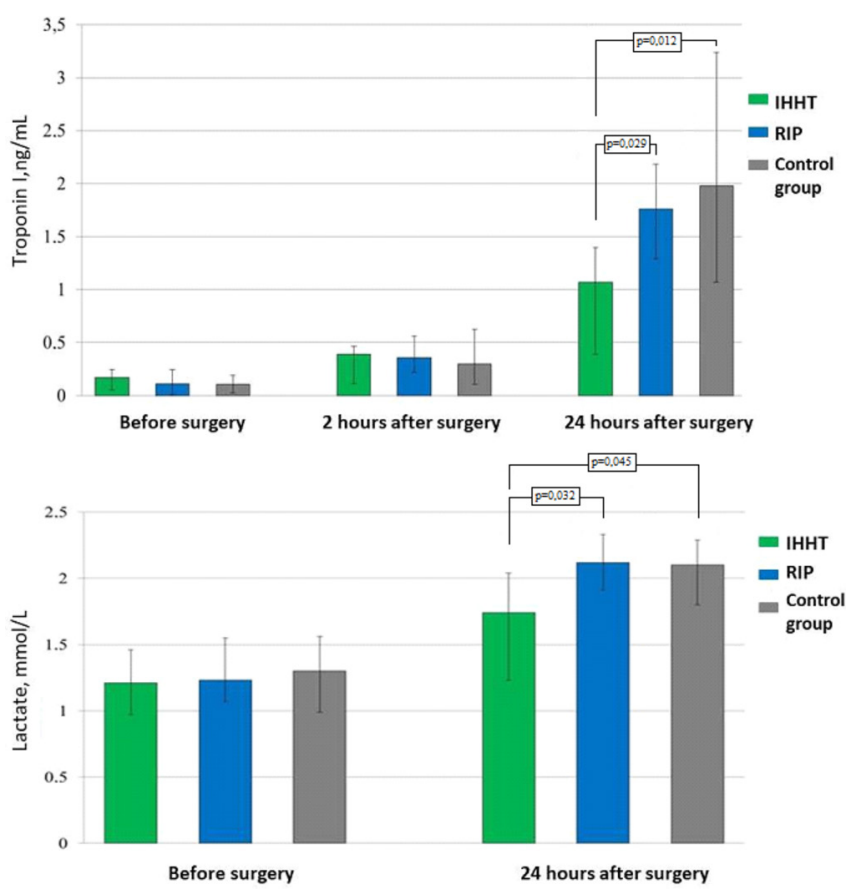

figure 2 Median values for troponin I and lactate before, 2 and 24 hours after surgery in patients with intermittent hypoxic-hyperoxoc training (IHHT), remote ischaemic preconditioning (RIP) and IHHT-controls.

that short-term exposure to mild hypoxia leads to functional and metabolic changes of the organism, which enhances its adaptation to hypoxia and also carries a wide range of protective properties. ${ }^{9}$ Although the exact mechanism of adaptation is not fully understood, it is known that one of the key mechanisms triggering adaptive responses to hypoxia is the induction of reactive oxygen species (ROS), which in turn promotes the activation of a number of protective mechanisms: antioxidant defence, anti-inflammatory potential and initiation of redox signalling. ${ }^{10}$ At the same time, energy efficiency of metabolic processes is improved and transport of oxygen into cell increases. ${ }^{12} 13$ There are data on the effectiveness of the use of normobaric hypoxic training to prevent complications in cardiac surgery. ${ }^{12}{ }^{14}$ However, the formation of sustainable adaptive protection using these methods requires a long time (3-5 weeks), which seriously limits the possibility of their use in clinical practice. Further studies have shown that interval hypoxic training can be improved by replacing normoxic pauses (re-oxygenation) by giving the patient a hyperoxic gas mixture, which led to the method of interval hypoxic-hyperoxic training. ${ }^{1015}$ Induction of ROS occurs at the beginning of re-oxygenation when the supplied gas mixture is switched from hypoxic to normoxic. By using consecutive hypoxic and hyperoxic instead of normoxic stimuli during training, ROS-induced signals may be reinforced without further deepening hypoxia. The rationale of such an approach is supported by the results of a study on the effectiveness of IHHT as a method to increase exercise tolerance in patients with stable coronary heart disease. ${ }^{101617}$

\section{Effects of RIP}

The history of research of RIP to prevent myocardial injury during vascular surgery extends back several decades. There are two ways in which the protective effect extends from the zone of local limb ischaemia to the whole organism: the formation and release of a number of biologically active substances into the systemic blood, including adenosine, bradykinin, endorphins, nitric oxide, interleukin 1a and micro-RNA 144, and a sensory-neural pathway. In 2006, the first study showing the cardioprotective effect of RIP in human during surgery for valve prosthesis has been published. ${ }^{5}$ However, results in regard to the potential of RPI to effectively protect the heart from ischaemic and reperfusion injury are controversial. Two major studies (RIPHeart and ERICCA) as well as several meta-analyses ${ }^{18-20}$ did not reveal any significant protective effect by the use of RIP before isolated CABG or in combination with valve replacement. Limitations are mainly associated with the use of different anaesthesia protocols and with different variants of the procedure. There is evidence that the anaesthetic propofol, which is most often used during cardiac surgery (as also in our patients), may abolish or neutralise the benefits of RIP. ${ }^{482122}$ However, there is no definitive answer so far. $^{20}$ There are studies that failed to show significant differences between groups with different anaesthetics. ${ }^{23}$ In a recent meta-analysis, no difference in the therapeutic effect of RIP was found when using propofol and volatile anaesthetics. ${ }^{24}$ Keeping this in mind, we tried to avoid such a potential interaction and thus a negative impact of anaesthetics on the procedures of preconditioning. Therefore, we decided to conduct RIP prior to initial anaesthesia. Due to the 'early window' of preconditioning, we expected that the protective effect would be preserved for 2-3 hours after RIP, and according to some authors even up to 4 hours after RIP. ${ }^{25}$ In our study, the time from the end of the RIP procedure until the end of $\mathrm{CPB}$ averaged 2 hours and $46 \mathrm{~min}$, whereas only in three patients the period exceeded 3 hours with a maximum time of 3 hours and $20 \mathrm{~min}$.

Furthermore, different authors used different limb selections or simultaneous application of several cuffs to different limbs to create local ischaemia. The upper limb has been used in the overwhelming majority of the last large studies and the procedure was carried out after the introduction of anaesthetics, which may reduce the effectiveness of the sensory-neural defense mechanism. In view of these results, we decided to use the lower extremity in our study (which has a much larger volume of muscle mass) and to perform the RIP procedure before the initiation of anaesthesia. This allowed to decrease the total anaesthesia time and to increase the potential of a stronger cardioprotective effect. In addition, it allowed blinding of anaesthesiologists and surgeons. This approach is also supported by results of a study of the late effect of RIP ('second' protective window of preconditioning), during which local ischaemia was 
created without the preliminary use of anaesthetics resulting in a significant reduction of the level of postoperative troponin. ${ }^{26}$

\section{Safety of ischaemic preconditioning}

The issue of safety of hypoxia in patients with ischaemic heart disease is of concern. There is a risk of provoking serious myocardial ischaemia with or without angina symptoms. However, this problem can be avoided to a great extent by performing a hypoxic test prior to the IHHT and by constant monitoring of oxygen saturation during the procedure. In case of a decrease of oxygen saturation of the blood below the predefined safety level, a switch to the supply of a hyperoxic gas mixture is done immediately. This may allow the patient's body to remain within the 'zone of incomplete compensation', which can trigger adaptation processes but does not lead to irreversible myocardial ischaemia.

It has to be noted that lactate levels after surgery were lower in patients who received training with IHHT, while lactate value in patients of the RIP group did not differ from those of the IHHT-control group. Lactate concentration in the blood increases in case of deficiency of oxygen supply to the tissues of the body. A relationship between the duration of cardiac arrest and increase of lactate in patients surviving paroxysmal ventricular fibrillation has been shown. ${ }^{27}$ In many studies, a direct correlation between the lactate level and mortality has been demonstrated in patients admitted to the intensive care unit irrespective of the diagnosis. ${ }^{28}$ Metabolic processes in cardiomyocytes change under conditions of ischaemia, the role of free fatty acids in the synthesis of ATP increases and, in parallel, the consumption of glucose decreases, and the heart turns from the consumer of lactate into its source. ${ }^{29}$ Thus, the energy efficiency of cellular metabolism decreases, intracellular acidosis increases and - as a result - the cardiac function progressively worsens. Normalization of metabolic processes in cardiomyocytes and optimisation of glucose use is an effective mechanism of cardioprotection in conditions of hypoperfusion. However, lactate may originate from different sources and both IHHT and RIP are systemic and not only local protective procedures.

Although the number of complications did not differ significantly between the three groups, the level of troponin was significantly lower in the IHHT group 24 hours after surgery compared with the other groups, whereas the value of troponin did not differ between the RIP and the IHHT-control group.

The absence of significant side effects and of patient refusals to perform IHHT should be noted. Performance of RIP without prior anaesthesia was accompanied by severe discomfort and was poorly tolerated. This led to the refusal of seven patients to participate in the study.

\section{Study limitations}

Although large, this was a single-centre trial and it was only powered adequately to analyse prospectively a surrogate cardiac biomarker which is cTnI. Future larger studies should be performed with adequate power to detect clinical rather than surrogate benefits. Our approach using both RIP and controls with usual care as comparators may be questioned, and doing a future trial with two rather than with three groups would be preferable to maximise power. The number of patients is relatively small and does not allow firm conclusions in regard to rare but important safety events. Causal relations between cardioprotection and outcome remain speculative. Results are not applicable to critically ill and unstable patients. Results may have been influenced by differences in the time and numbers of application (four IHHT vs one RIP) and delayed versus early time windows. There is the possibility that ischaemia-reperfusion time was beyond the protective time window, at least in some cases. In regard to practical aspects, there may be barriers for the use of IHHT due to the fact that special equipment and close monitoring are necessary for the intervention. Our results are restricted to patients with CABG surgery and have to be extrapolated to other types of cardiac surgery with caution. Furthermore, the use of IHHT training before cardiac surgery is restricted to patients with elective surgery.

\section{CONCLUSIONS}

For the first time, safety and effectiveness of intermittent hypoxic-hyperoxic training as a method of preconditioning and cardioprotection during CABG surgery with $\mathrm{CPB}$ are demonstrated in this randomised controlled clinical trial. Troponin dynamics indicate that patients in the IHHT group had less damage of myocardium in the postoperative period and they also showed a lower degree of serum lactate accumulation compared with RIP patients and IHHT-controls. The benefits of IHHT compared with RIP may be explained by a stronger systemic effect of hypoxia-hyperoxia on the patient's body compared with local ischaemia of an individual limb. Further studies are required to determine whether it is possible to protect both the heart and other organs from ischaemia/reperfusion injury by IHHT and larger trials should be done with adequate power to detect clinical rather than surrogate marker benefits.

Contributors DST: study design, research protocol, data collection, data analysis and interpretation, writing and final approval of the manuscript. PYK: study design, research protocol, final approval of manuscript. ALS: study design, research protocol, final approval of manuscript. OSG: study design, data analysis and interpretation, final approval of manuscript. RNK: study design, research protocol, final approval of manuscript. AlK: data collection, data analysis and interpretation final approval of manuscript. LPS: data collection, data analysis, final approval of manuscript. EVl: data collection, data analysis, final approval of manuscript. YZ: study design, study protocol, final approval of manuscript. HS: data analysis and interpretation, writing and final approval of manuscript. DST, PYK, OSG, YZ and HS are all responsible for the overall content as guarantors.

Funding The authors have not declared a specific grant for this research from any funding agency in the public, commercial or not-for-profit sectors.

Competing interests None declared.

Patient consent Obtained. 
Ethics approval Institutional Review Board of the IE Sechenov First Moscow State Medical University, Moscow, Russia.

Provenance and peer review Not commissioned; externally peer reviewed.

Data sharing statement No additional data are available.

Open access This is an open access article distributed in accordance with the Creative Commons Attribution Non Commercial (CC BY-NC 4.0) license, which permits others to distribute, remix, adapt, build upon this work non-commercially, and license their derivative works on different terms, provided the original work is properly cited, appropriate credit is given, any changes made indicated, and the use is non-commercial. See: http://creativecommons.org/licenses/by-nc/4.0/

\section{REFERENCES}

1. Møller $\mathrm{CH}$, Penninga L, Wetterslev J, et al. Off-pump versus onpump coronary artery bypass grafting for ischaemic heart disease. Cochrane Database Syst Rev 2012;3:CD007224.

2. Heusch G, Bøtker HE, Przyklenk K, et al. Remote ischemic conditioning. J Am Coll Cardiol 2015;65:177-95.

3. Kleinbongard P, Skyschally A, Heusch G. Cardioprotection by remote ischemic conditioning and its signal transduction. Pflügers Archiv European Journal of Physiology 2017;469:159-81.

4. Thielmann M, Kottenberg E, Kleinbongard P, et al. Cardioprotective and prognostic effects of remote ischaemic preconditioning in patients undergoing coronary artery bypass surgery: a single-centre randomised, double-blind, controlled trial. Lancet 2013;382:597-604.

5. Cheung MM, Kharbanda RK, Konstantinov IE, et al. Randomized controlled trial of the effects of remote ischemic preconditioning on children undergoing cardiac surgery: first clinical application in humans. J Am Coll Cardiol 2006;47:2277-82.

6. Zhou W, Zeng D, Chen R, et al. Limb ischemic preconditioning reduces heart and lung injury after an open heart operation in infants. Pediatr Cardiol 2010;31:22-9.

7. Kolh P, Windecker S, Alfonso F, et al. 2014 ESC/EACTS Guidelines on myocardial revascularization: The Task Force on Myocardial Revascularization of the European Society of Cardiology (ESC) and the European Association for Cardio-Thoracic Surgery (EACTS). Developed with the special contribution of the European Association of Percutaneous Cardiovascular Interventions (EAPCI). Eur J Cardiothorac Surg 2014;46:517-92.

8. Kostin Al, Glazachev OS, Platonenko AV, et al. A device for performing complex interval normobaric hypoxic-hyperoxic training in a person. The patent of the Russian Federation for the invention №2365384, 2009.

9. Liamina NP, Karpova ÉS, Kotel'nikova EV. [Adaptation to hypoxia and ischemic preconditioning: from basic research to clinical practice]. Clinical Medicine 2014;2:23-9.

10. Glazachev OS, Yu.M P, Urinsky AM. Increased tolerance to physical exertion in patients with coronary heart disease by adaptation to hypoxia-hyperoxia. Cardiovascular therapy and prevention 2014;13:16-21.

11. Burtscher M, Gatterer $\mathrm{H}$, Szubski $\mathrm{C}$, et al. Effects of interval hypoxia on exercise tolerance: special focus on patients with CAD or COPD. Sleep Breath 2010;14:209-20.

12. Gelis LG, Dubovik TA, Rachok LV. Influence of intermittent normobaric hypoxia on the compensatory and adaptive capabilities of the organism in the complex preoperative preparation for cardiosurgical treatment of patients with ischemic cardiomyopathy. Cardiology in Belarus 2013;5:19-38.
13. Powell FL, Garcia N. Physiological effects of intermittent hypoxia. High Alt Med Biol 2000;1:125-36.

14. Maslov LN, Yu BL, T VE. Hypoxic preconditioning as a new approach to the prevention of ischemic and reperfusion injuries of the brain and heart. Angiology and vascular surgery 2011;17:27-36.

15. Sazontova TG, Glazachev OS, Bolotova AV, et al. [Adaptation to hypoxia and hyperoxia improves physical endurance: the role of reactive oxygen species and redox-signaling]. Ross Fiziol Zh Im I M Sechenova 2012;98:793-807.

16. Glazachev O, Kopylov P, Susta D, et al. Adaptations following an intermittent hypoxia-hyperoxia training in coronary artery disease patients: a controlled study. Clin Cardiol 2017;40:370-6.

17. Syrkin AL, Glazachev OS, Kopylov FY, et al. [Adaptation to intermittent hypoxia-hyperoxia in the rehabilitation of patients with ischemic heart disease: exercise tolerance and quality of life]. Kardiologiia 2017;57:10-16.

18. Pierce B, Bole I, Patel V, et al. Clinical outcomes of remote ischemic preconditioning prior to cardiac surgery: a metaanalysis of randomized controlled trials. J Am Heart Assoc 2017:6:e004666.

19. Haji Mohd Yasin NA, Herbison P, Saxena P, et al. The role of remote ischemic preconditioning in organ protection after cardiac surgery: a meta-analysis. J Surg Res 2014;186:207-16.

20. Heusch G, Gersh BJ. ERICCA and RIPHeart: two nails in the coffin for cardioprotection by remote ischemic conditioning? Probably not! Eur Heart J 2016;37:200-2.

21. Kottenberg E, Thielmann M, Bergmann L, et al. Protection by remote ischemic preconditioning during coronary artery bypass graft surgery with isoflurane but not propofol-a clinical trial. Acta Anaesthesiol Scand 2012;56:30-8.

22. Kottenberg E, Musiolik J, Thielmann M, et al. Interference of propofol with signal transducer and activator of transcription 5 activation and cardioprotection by remote ischemic preconditioning during coronary artery bypass grafting. J Thorac Cardiovasc Surg 2014;147:376-82.

23. Karami A, Khosravi MB, Shafa M, et al. Cardioprotective effect of extended remote ischemic preconditioning in patients coronary artery bypass grafting undergoing: a randomized clinical trial. Iran $\mathrm{J}$ Med Sci 2016;41:265-74.

24. Benstoem C, Stoppe C, Liakopoulos OJ. Remote ischaemic preconditioning for coronary artery bypass grafting (with or without valve surgery). Cochrane Database Syst Rev 2017;5:CD011719.

25. Moses MA, Addison PD, Neligan PC, et al. Inducing late phase of infarct protection in skeletal muscle by remote preconditioning: efficacy and mechanism. Am J Physiol Regul Integr Comp Physiol 2005;289: R1609-R1617.

26. Wagner R, Piler P, Bedanova $\mathrm{H}$, Wagner R, Piler P, Bedanova $H$, et al. Myocardial injury is decreased by late remote ischaemic preconditioning and aggravated by tramadol in patients undergoing cardiac surgery: a randomised controlled trial. Interact Cardiovasc Thorac Surg 2010;11: 758-62.

27. Momiyama Y, Yamada W, Miyata K, et al. Prognostic values of blood $\mathrm{pH}$ and lactate levels in patients resuscitated from out-of-hospital cardiac arrest. Acute Med Surg 2017;4:25-30.

28. Kruse O, Grunnet N, Barfod C. Blood lactate as a predictor for in-hospital mortality in patients admitted acutely to hospital: a systematic review. Scand J Trauma Resusc Emerg Med 2011;19:74.

29. Jaswal JS, Keung W, Wang W, et al. Targeting fatty acid and carbohydrate oxidation - a novel therapeutic intervention in the ischemic and failing heart. Biochim Biophys Acta 2011;1813:1333-50. 